\title{
MODELING SURGE-DEPENDENT VEGETATION EFFECTS ON HURRICANE-GENERATED WAVES
}

\begin{abstract}
Qin Chen ${ }^{1}$, Haihong Zhao ${ }^{2}$ and Don $\mathrm{Liu}^{3}$
The study utilizes a coupled wave-surge-vegetation modeling system to quantify the effects of salt marsh vegetation on hurricane-generated waves. The wave model incorporates the energy dissipation model of Chen and Zhao (2012) for random waves over vegetation. The storm surge model incorporates the vegetal drag for both rigid and flexible types of vegetation. The surge and wave models with the vegetation effects are coupled, allowing the spatially and temporally varying vegetation heights, water levels and depth-averaged currents from the storm surge model to be fed into the wave model. Numerical experiments have revealed that vegetation can change the surge height and a storm surge can change the vegetation height. Both control the wave reduction rate in flooded wetlands. The impact of vegetation on hurricane-generated waves consists of indirect and direct effects. The former is caused by the changes in surge height due to vegetation. The latter comes from the direct interaction between vegetation and the oscillatory motion of surface waves. It has been found that flexible marsh vegetation deflects under the hydrodynamic force produced by a hurricane. The deflected height not only reduces the flow resistance in the surge model, but also decreases the energy dissipation caused by vegetation in the wave model. Consequently, neglecting plant flexibility may lead to overestimates of vegetation effects and exaggeration of wetland potential for flood risk reduction.
\end{abstract}

Keywords: vegetation effect; wave dissipation; storm surge; hurricane; numerical modeling; coastal wetlands

\section{INTRODUCTION}

Along many coastal regions of the world, wetlands and coastal forests provide a natural defence line against storm surge and waves. Surge reduction and wave attenuation have been recognized in previous laboratory experiments and numerical modelling studies (Resio and Westerink 2008; Lövstedt and Larson 2010; Gedan et al. 2011; Shepard et al. 2011). Numerical models have been employed to investigate the effects of vegetation and routinely utilized to predict storm surge and waves for emergency preparedness and for coastal resources management (Loder et al. 2009; Wamsley et al. 2009; Wamsley et al. 2010). Conventionally, vegetation effects are incorporated in numerical models through the Manning's roughness coefficient or empirical formulations that parameterize vegetal drag coefficients. Though a number of formulations have been tested with limited laboratory studies (Wu et al. 1999; Copeland 2000; Kouwen and Fathi-Maghadam 2000; Wilson 2007), there is a scarcity of verification with field data. Moreover, little is known about the interaction among waves, surge and natural vegetation which deforms under strong forcing.

The objective of the present study is to quantify wave attenuation caused by coastal marshes in a high energy environment associated with tropical cyclones. An improved model system coupling surge, waves and vegetation is applied with a bulk vegetation coefficient that was determined using field data collected during a tropic storm. The model system has been tested against laboratory experiments. Surge-dependent wave attenuation is investigated through a parametric study with a series of numerical experiments.

\section{NUMERICAL MODELS}

In this study, the one-way coupling between a two-dimensional storm surge model and a spectral wave model is adopted with the focus on the quantification of wave attenuation. Effects of vegetation are considered in both the wave model and the surge model. In the presence of vegetation, not only the vegetation-affected depth-averaged currents and water levels, but also the deflected vegetation heights estimated in the surge model, are fed into the wave model. The following sections present a summary of the wave model, surge model and the coupling with the effects of deformable vegetation.

\section{Wave Attenuation Model}

Dalrymple et al. (1984) were the first to utilize the wave drag force on a rigid cylinder of small diameter to estimate wave energy dissipation due to the interaction of oscillatory fluid motion and plant shoots. The method was further extended by Mendez and Losada (2004) to, narrow-banded, random waves, which uses the peak wave period as a constant, representative period and the Rayleigh distribution (RD) of wave heights. The approach has been implemented into the widely used, third

\footnotetext{
${ }^{1}$ Department of Civil \& Environmental Engineering, and Center for Computation and Technology, Louisiana State University, Baton Rouge, LA 70803, USA

2 ARCADIS-US, 10352 Plaza Americana Dr., Baton Rouge, LA 70816, USA

${ }^{3}$ Mathematics and Statistics, Louisiana Tech University, Ruston, LA 71272, USA
} 
generation spectral wave prediction model, SWAN (Simulation of Waves in Nearshore) with the peak period replaced by the mean period.

Chen and Zhao (2012) extended the studies of wave attenuation models and presented theoretical and numerical analyses of random wave attenuation attributable to vegetation. It has been found that the RD-based formulation is only accurate for a narrow-banded, random wave field. The use of the peak period in the RD-based model is sensitive to the spectral shape. A new model for random waves was introduced by Chen and Zhao (2012) on the basis of Hasselmann and Collins' (HC) treatment of energy dissipation of random waves due to the bottom friction. The dissipation rate due to vegetation is expressed as a function of vegetation properties (stem diameter, plant population density and vegetation bulk drag coefficient) and the root-mean-squared orbital velocity in the stem layer. The approach results in good comparison with measured root-mean-square wave heights over vegetation. Moreover, the HC-based model estimates an increased spectral width as the waves propagate over the vegetation whereas the RD-based model results in a decrease in the spectral width parameter. A field study of wave damping by reeds (Lövstedt and Larson 2010) shows the transformation of the probability distribution function (PDF) of wave heights and their observed change in the PDF suggests that the spectral width of the wave field may also change. The change of spectral width due to vegetation damping has been confirmed by recent field measurements collected during a tropical storm (Jadhav and Chen 2012).

The HC-based model is implemented into SWAN in the present study and tested against laboratory experiments performed by Lovas (2000). Details are in the section of "MODEL TESTS".

\section{Surge Attenuation Model}

Potential benefits of coastal wetlands for reducing storm surge heights depend on wetland size, wetland vegetation properties (biological and biomechanical) and wetland health conditions that affect the vegetation-induced flow resistance. The dominant vegetative resistance to the flow in various circulation or storm surge models is parameterized as an analog of the bottom friction using an enhanced, static Manning's coefficient $(n)$, which may not be adequately accurate according to recent studies (e.g., Kouwen and Li 1980; Wu et al. 1999; Freeman et al. 2000; Wilson and Horritt 2002; Carollo et al. 2005; Wilson 2007). In reality, the Manning's coefficient has been found to vary spatially and temporarily (Shih and Rahi 1982; Doncker et al. 2009). At different flow stages (varying flow depth and flow velocity), the Manning's coefficient has different values (Wu et al. 1999; Wilson and Horritt 2000; Wilson 2007).

A lumped value of Manning's coefficient may not be appropriate, especially in the coastal area during a hurricane event. Velocities (>1 m/s) common to surge events are sufficient to bend flexible vegetation, such as Spartina alterniflora, Spartina patens and Juncus roemerianus, commonly found along the northern coast of the Gulf of Mexico. The plant rigidity is a crucial parameter to determine the degree of tilt which consequently alters the flow resistance and the wave attenuation rate. Experimental studies have shown that empirical formulations of an equivalent Manning's coefficient $\left(n_{e}\right)$ of deformable shrubs and woody vegetation converge for emergent and submerged conditions (Copeland 2000; Freeman et al. 2000). The experimental studies indicate that the critical water depth is equal to $80 \%$ of the erect vegetation height, smaller than one as it would be for rigid vegetation. Zhao and Chen (2012) implemented three formulations in a horizontally two-dimensional storm surge model to consider the vegetal drag of rigid cylinders and deformable plants for a full range of submergence. For a deformable plant, the flow resistance and the deflected vegetation height are obtained by solving a deformation relation and a flow resistance law iteratively. The deformation relation introduced by Kouwen and Li (1980) was adopted; however, site-specific field experiments are suggested to either determine the constants in the formulation or to develop a new deformation relationship applicable to the local vegetation. The storm model incorporating effects of deformable vegetation has been tested against experimental data and is adopted in the present study.

\section{Coupled Surge-Wave-Vegetation Models}

During a high energy event, such as a hurricane, wind waves ride on the surge water and the waveinduced setup increases the water level on top of the storm surge. The interaction becomes more complicated with the interference of vegetation. A model system coupling both the wave model and the storm surge model with deformable vegetation is necessary to investigate the storm surge development and attenuation on coastal wetlands, and wind wave generation, propagation and dissipation in the presence of vegetation.

The interaction of waves and an ambient current is significant in the presence or absence of wetlands (e.g. Chen et al. 2005; 2007). The interplay can be enhanced during a hurricane event when both short 
waves and the long surge wave are high. The storm surge makes the total water depth deeper, which allows larger waves to propagate in inundated areas. Strong currents during flooding and receding of the surge water have influences on wave triad interactions (Chen et al. 1999). The wave-induced setup in return elevates the surge level, which ought to be included in the storm surge model (Dean and Bender 2006; Resio and Westerink 2008). Within the sub-layer of the wave bottom boundary, the bottom shear stress increases as a result of the nonlinear wave-current interaction. When wetlands are considered, the wave-current interaction becomes more complicated because of the nonlinear nature of the resistance force due to vegetation elements (Li and Yan 2007; Patil and Singh 2009). In this study, the one-way coupling between the surge model and the wave model is considered because the wave attenuation is focused. Water levels and depth-averaged currents are simulated in the surge model with effects of vegetation. In addition to water depths and velocities, temporarily and spatially varying deflected vegetation heights determined in the surge model serve as an input to the vegetation dissipation model in SWAN.

\section{MODEL TESTS}

\section{Lovas (2000) Experiments}

The laboratory data of Lovas (2000) were used to validate the numerical model for the transformation, vegetation-induced dissipation and breaking of random waves. The experiments were carried out in a 40-m long and 5-m wide wave flume at SINTEF (Norway). The flume was partitioned to form a $0.6 \mathrm{~m}$ wide channel. A vegetation field of $7.27-\mathrm{m}$ in length was located at the center of the channel in the longitudinal direction, which was covered by artificial kelps (bottom panel in Figure 1). The kelp plants were flexible, thin stripes with a frontal width of $0.025 \mathrm{~m}$ and a height of $0.2 \mathrm{~m}$. The maximum number of uniformly distributed plants per unit horizontal area was $\mathrm{N}=1200 \mathrm{units} / \mathrm{m}^{2}$. The root-mean-square wave heights were obtained for 13 sets of experiment. In each run, free surface oscillations were measured at 10 wave gauges with the first one representing the offshore wave conditions and the rest on the sloping beach.

In the wave attenuation model, a drag coefficient for the overall condition of the kelp field needs to be defined or calibrated. Mendez and Losada (2004) found that the bulk drag coefficient depends on the flow around the plants and vegetation properties. Their analysis showed that a relationship exists between the bulk drag coefficient and a modified Keulegan-Capenter parameter, which depends on the horizontal orbital velocity, peak wave period, vegetation frontal width, and the relative height of the plants. Because the relationship was obtained based on experiments over the kelp field with the same properties as that in Lovas (2000), the drag coefficient in the wave attenuation model was adopted from Mendez and Losada's (2004) study.
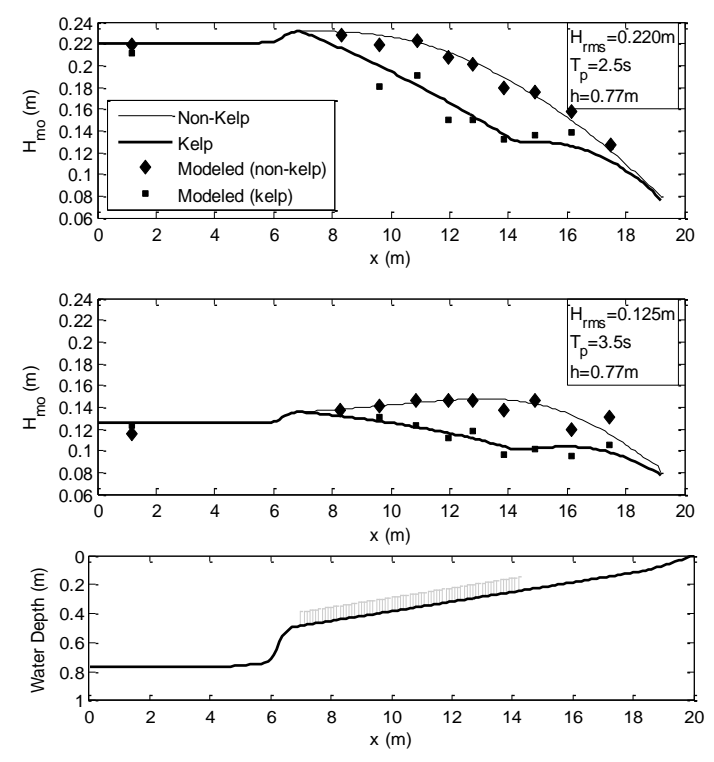

Figure 1. Comparisons of modeled (solid lines) and measured (symbols) significant wave heights (top two panels); Model domain setup (bottom panel) 
Figure 1 shows comparisons of the modeled and measured wave heights for two runs with and without kelp. The top panel shows the comparison for wave breaking conditions and the second one is for non-breaking conditions. The good agreement for both breaking and non-breaking conditions illustrates the ability of the model to predict wave dissipation due to vegetation on a sloping beach.

\section{Flow Resistance due to Rigid Vegetation}

The flow resistance due to vegetation was computed in the surge model. During a hurricane, vegetation experiences emergent, near emergent and submerged conditions as the storm surge water intrudes and retreats. The near emergent stage may be critical for understanding not only the surge reduction but also the vegetation mortality as the drag force is significant under near emergent conditions (Nepf and Vivoni 2000; Nikora et al. 2001). In addition, the vegetation flexibility as one of the biomechanical properties is a key parameter to determine the vegetal drag under strong currents. Because of the inclination of stems, the vegetation layer thickness decreases so does the vegetative flow resistance (Kouwen and Li 1980; Tsujimoto et al. 1996; Freeman et al. 2000).

In this study, one of the laboratory experiments (Case A) performed by Tsujimoto and Kitamura (1995) was used to test the model for emergent vegetation planted in a compound channel. The flume was $12 \mathrm{~m}$ long and $0.4 \mathrm{~m}$ wide with emergent bamboos covering a $0.12 \mathrm{~m}$-wide vegetation zone (Figure 2). The stem population density of bamboos was $1,275.5 \mathrm{~m}^{-2}$. Bamboos with a diameter of 0.15 $\mathrm{cm}$ were distributed in a parallel pattern and the spacing of vegetation elements was $2.8 \mathrm{~cm}$. The flume had a mean bed slope of $1.7 \times 10^{-3}$, a mean flow depth of $4.57 \mathrm{~cm}$, a cross-section-averaged channel flow velocity of $32.0 \mathrm{~cm} / \mathrm{s}$, and a friction factor of $3.8 \times 10^{-3}$ in the main course. These experiment parameters were used as an input to the numerical model. Details were given in Tsujimoto and Kitamura (1995), and Zhao and Chen (2012).

Figure 2 shows good agreement between the numerical and experimental results. The numerical model shows that the bamboo field considerably reduces the flow velocity in the vegetation zone (VZ), consistent with the laboratory measurements. More tests of the surge model can be found in Zhao and Chen (2012).
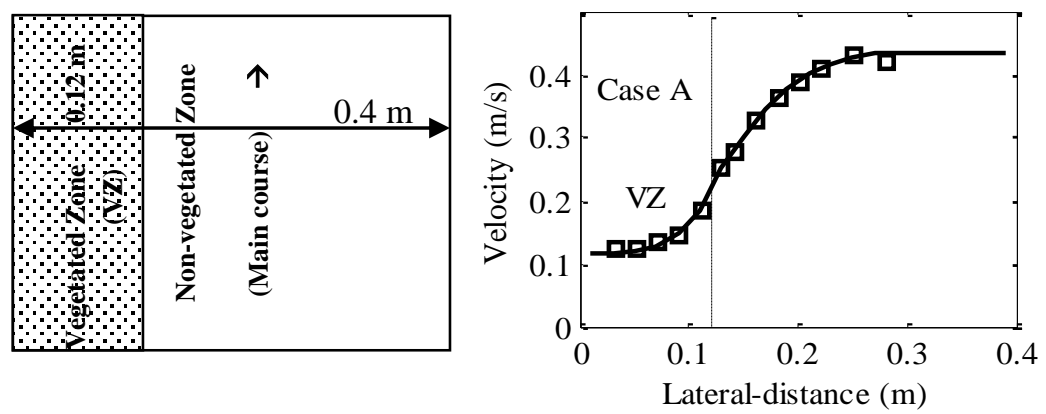

Figure 2. Plane view of Tsujimoto and Kitamura's (1995) experiment (left); Comparison of measured (squares) and modeled (solid line) depth-averaged velocities for Case A (right)

\section{PARAMETRIC STUDY}

A parametric study was carried out to quantify wave attenuation due to deformable vegetation during a hurricane. The model domain is a simplified prototype of Breton Sound, Louisiana. The Breton Sound estuary is located on the eastern side of Mississippi River and confined by the Mississippi River Gulf Outlet (MRGO) to the north-east. The upper region of the estuary is mainly covered with intermediate brackish and salt marshes. Bathymetry/topography in the upper region of Breton Sound was averaged to generate a one-dimensional, continuous bed with only longitudinal variation. In the field, the wetlands are in fragments due to natural ponds and bayous as well as manmade channels. The fragmentation of the wetlands is not considered in the present study. In the simplified domain, plants are uniformly distribution in the upper region similar to the field conditions. Except for the fragmentation condition, other properties of the wetland marshes are kept as the measured values of Juncus roemarianus (Zone 1) and Spartina alternaflora (Zone 2)

Figure 3 summarizes the numerical experiments (the third column) performed in the parametric study and the input/output of each run. In total, six experiments of wave attenuation are carried out with three sets of hydrodynamic input, which were generated using three options of vegetative 
resistance (the second column) in the surge model with one set of driving force (the first column). The output of the wave attenuation model is significant wave heights and labeled in the fourth column for future comparison.

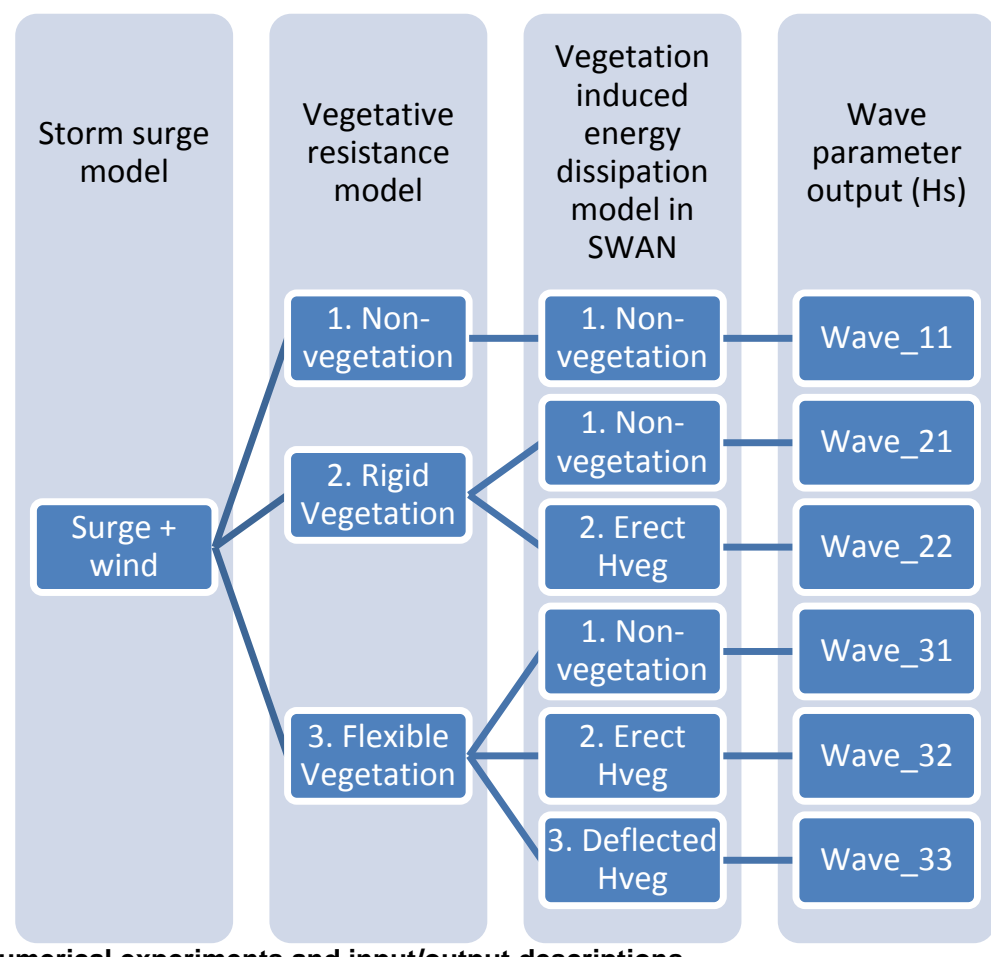

Figure 3. Design of numerical experiments and input/output descriptions

Most studies of wave attenuation caused by vegetation focused on wave energy dissipation due to the interaction of the oscillatory motion and rigid plant stems in a stationary state. However, during a hurricane event, wave heights, especially in the inundated areas, are also affected by surge heights and currents, which are altered by the presence of vegetation (Zhao and Chen 2012). Therefore, influences of vegetation on wave heights consist of an indirect portion due to the vegetation-affected storm surge condition and a direct portion due to vegetation-wave interaction.

\section{Indirect Effect of Vegetation on Wave Height}

In the surge model, three options of flow resistance are available: non-vegetation, rigid vegetation and deformable vegetation. The non-vegetation model produces the least flow resistance while the rigid vegetation model produces the highest resistance. Consequently, the peak surge heights vary with different vegetation models. Due to the increased flow resistance by vegetation, both the rigid vegetation model and the deformable vegetation model result in lower surge heights in the upland area and a swell of water surface near the edge of the marshland. Figure 4 displays the peak surge heights and maximum significant wave heights in the longitudinal direction of the model domain. The surge heights are the output from the storm surge model (Zhao and Chen 2012), and the corresponding time series of water levels and depth-averaged currents are fed into SWAN. The maximum significant wave heights are obtained from SWAN without activating the vegetation dissipation model. The increased surge heights on the seaward side of the marshland result in larger waves while the reduced surge heights due to the vegetation in the marshland limit the wave growth. Therefore, effects of vegetation are passed on to the wave height reduction indirectly through the reduced surge levels.

\section{Direct Effect of Vegetation on Wave Height}

Wave energy dissipation due to the vegetal drag is considered as the direct effect of vegetation. With the input of water levels over the rigid vegetation field, two experiments are carried out with (Wave_22) and without (Wave_21) vegetation-induced dissipation in the wave model. The difference in the maximum significant wave heights reveals the potential of marshlands to damp wave energy (Figure 5-a). Under the same input of water levels, wave heights in the vegetation zone are much smaller than those without vegetation. Another set of experiments with the input of water levels over flexible vegetation are performed to demonstrate the effects of vegetation and vegetation flexibility. 
Using the same time series of water levels, three runs, namely non-vegetation (Wave_31), rigid vegetation (Wave_32) and deformable vegetation (Wave_33), are carried out. The comparison of the maximum significant wave heights among the three experiments is shown in Figure 5-b. In the vegetation zone (Zone 1, Juncas roemarianus and Zone 2, Spartina alternaflora), results from both the rigid vegetation run (solid line) and deformable vegetation run (dashed line) are lower than the nonvegetation results (red line). Because the deformable vegetation model considers the temporally and spatially varying vegetation heights, the model results show slightly larger wave heights than the rigid vegetation model results.

Note that Zone 2 is covered by relatively short and rigid Spartina alternaflora. Under the same driving condition, the vegetation in Zone 2 is barely bent in the surge model, which is reflected in the in-differentiable wave heights given by the deformable vegetation model (Wave_33) and the rigid vegetation model (Wave_32). Differences in wave heights between deformable and rigid vegetation models are only seen in Zone 1, where relatively tall and flexible Juncus Roemarianus is present.
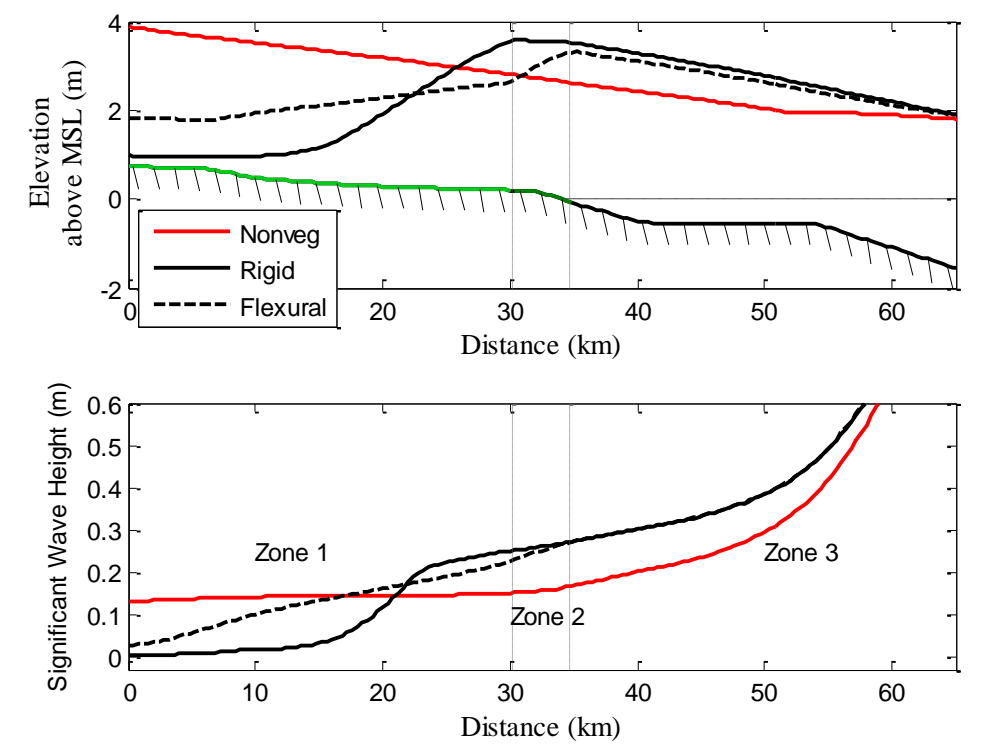

Figure 4 Modeled peak surge heights and maximum significant wave heights of three runs: Wave_11, Wave_21 and Wave_31
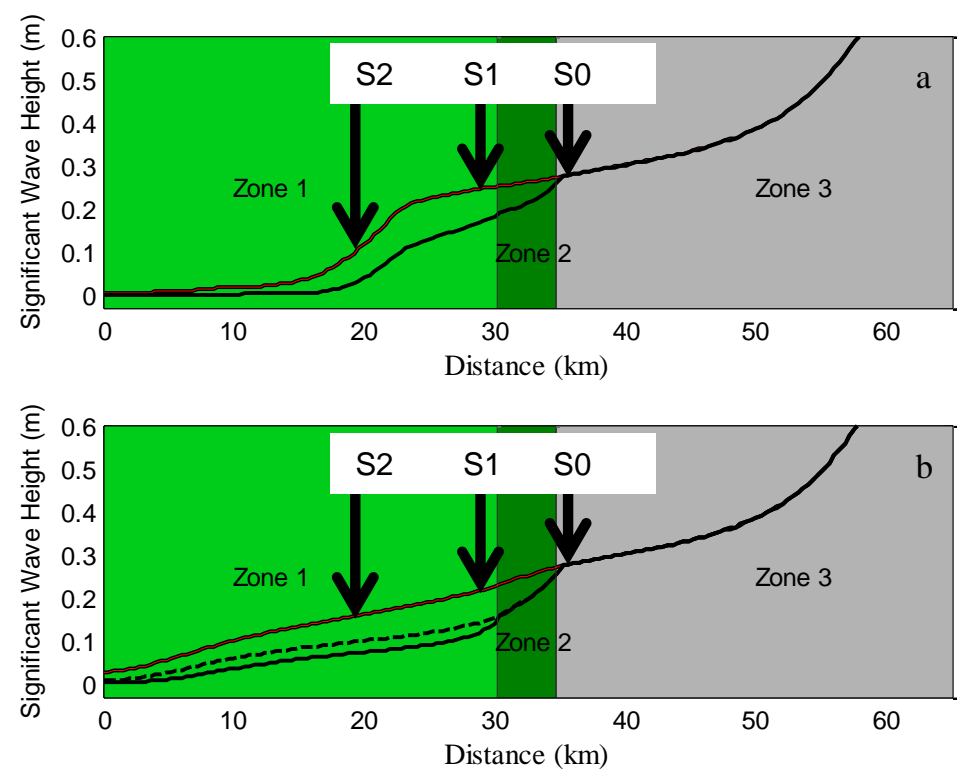

Figure 5 Comparisons of wave heights among different vegetation dissipation models 
To quantify the effects of vegetation on wave attenuation, the wave heights and reduction rates at two wetland stations (S1 and S2) are extracted from the model output. Table 1 shows the maximum significant wave heights at S0 (the offshore station), S1 and S2, and the reduction rates at S1 and S2. The reduction rate is computed as the percentage of the reduced wave height at the wetland station normalized by the wave height at the offshore station seaward of the marshland edge. It is noticed that the simulation without vegetation in both the surge model and wave model shows the smallest wave height reduction, which is mainly caused by depth-limited wave breaking. If vegetation effects are included in the surge model only, the modeled wave heights are smaller at S2 in the rigid vegetation run (Wave_21) than those in the non-vegetation run (Wave_11). On the contrary, the wave height at S2 from the flexible vegetation run (Wave_31) is higher than that of Wave_11 because the elevated surge height at the seaward edge of the marshland due to the presence of vegetation permits larger waves at S2 if no vegetation-induced wave attenuation is included in the wave model. This case not only illustrates the indirect effect of vegetation on waves through the change in surge levels, but also demonstrates that the direct effect of vegetation on waves is important and should be taken into account in the wave model. Vegetation effects should be considered in both the surge and wave models.

However, if rigid vegetation is assumed in both surge model and wave model, the modeled wave height at S2 has the smallest value due to the overestimates of vegetative resistance to the surge and vegetation-induced dissipation to waves. If deformable vegetation is assumed in both surge model and wave model, the modeled wave height $(0.10 \mathrm{~m}$ at S2 in Wave_33) turns out to be close to the result $(0.11 \mathrm{~m}$ at $\mathrm{S} 2)$ in Wave_21. Tall and flexible marsh vegetation does not behave like a rigid cylinder, especially under the hurricane forcing. Flow resistance and wave energy dissipation due to deformable vegetation have to appropriately be implemented into a surge model and a wave model, respectively.

\begin{tabular}{|c|c|c|c|c|c|c|c|}
\hline \multicolumn{2}{|c|}{ Vegetation options } & \multirow{2}{*}{$\begin{array}{c}\text { Experiment } \\
\text { label }\end{array}$} & \multirow{2}{*}{$\begin{array}{c}\text { H_S0 } \\
(\mathrm{m})\end{array}$} & \multicolumn{4}{|c|}{$\begin{array}{l}\text { Wave height and reduction rate at } \\
\text { inland stations: } S 1 \text { and } S 2\end{array}$} \\
\hline $\begin{array}{l}\text { In surge } \\
\text { model }\end{array}$ & $\begin{array}{l}\text { In wave } \\
\text { model }\end{array}$ & & & $\underset{(\mathrm{m})}{\mathrm{H}}$ & $\begin{array}{l}\text { r_S1 } \\
(\%)\end{array}$ & $\underset{(\mathrm{m})}{\mathrm{H} \text { _S2 }}$ & $\begin{array}{l}\text { r_S2 } \\
(\%)\end{array}$ \\
\hline \multicolumn{2}{|c|}{ No vegetation } & Wave_11 & 0.17 & 0.15 & 11.8 & 0.14 & 17.6 \\
\hline \multirow{2}{*}{$\begin{array}{c}\text { Rigid } \\
\text { vegetation }\end{array}$} & No-veg. & Wave_21 & 0.27 & 0.25 & 7.4 & 0.11 & 59.3 \\
\hline & Rigid-veg. & Wave_22 & 0.27 & 0.17 & 37.0 & 0.03 & 88.9 \\
\hline \multirow{3}{*}{$\begin{array}{l}\text { Flexural } \\
\text { vegetation }\end{array}$} & No-veg. & Wave_31 & 0.27 & 0.22 & 18.5 & 0.16 & 40.7 \\
\hline & Rigid-veg. & Wave_32 & 0.27 & 0.12 & 55.6 & 0.07 & 74.1 \\
\hline & Flex.-veg & Wave_33 & 0.27 & 0.14 & 48.1 & 0.10 & 63.0 \\
\hline
\end{tabular}

In Table 1, two wetland stations are listed, where wave height reduction rates are presented for comparison with the results without the consideration of vegetation effects. Note that the wave height reduction rates at $\mathrm{S} 2$ are greater in all vegetation-involved cases than those in the non-vegetation baseline case. However, this is not always the case at S1. Because S1 is located close to the edge of the marshland, where the surge height is elevated due to the blockage of vegetation, the greater water depth allows larger waves to propagate into the vegetation zone.

\section{SUMMARY AND CONCLUSIONS}

The paper utilizes a coupled wave-surge-vegetation modeling system to quantify the effects of salt marsh vegetation on hurricane-generated waves. The wave model incorporates the energy dissipation model of Chen and Zhao (2012) for random waves over vegetation. The storm surge model incorporates the vegetal drag for both rigid and flexible types of vegetation (Zhao and Chen 2012). The surge and wave models with the vegetation effects are coupled, allowing the spatially and temporally varying vegetation heights, water levels and depth-averaged currents from the storm surge model to be fed into the wave model. Both wave and surge models have been tested against available laboratory data. Good agreement has been found. A parametric study was carried out to understand how natural vegetation influences wind waves in inundated coastal wetlands during a hurricane event.

Numerical experiments using the coupled wave-surge-vegetation modeling system have revealed that vegetation changes the surge height and a storm surge can change the vegetation height. Both control the wave reduction rate in flooded wetlands. The impact of vegetation on hurricane-generated waves consists of indirect and direct effects. The former is caused by the changes in surge height or flood depth due to vegetation. The latter comes from the direct interaction between vegetation and the 
oscillatory motion of surface waves. It has been found that tall and flexible marsh vegetation deflects under the hydrodynamic force generated by a hurricane. The deflected vegetation height not only reduces the flow resistance in the surge model, but also decreases the energy dissipation caused by vegetation in the wave model. Consequently, neglecting the plant flexibility would lead to overestimates of vegetation effects and exaggeration of wetland potential for flood risk reduction.

The coupled wave-surge-vegetation models have produced promising results, including vegetationinduced flow resistance, and wave attenuation under lab and field conditions. Comparisons with field observations of hurricane-generated waves and storm surge, however, are needed. Although it is difficult to conduct wave measurements or to collect biomechanical data of vegetation in inundated wetlands during a hurricane event, recent field experiments during Tropical Storm Lee (2011) and Hurricane Isaac (2012) provided valuable datasets for model validation. Results will be reported on in the near future.

\section{ACKNOWLEDGMENTS}

Funding provided by the National Science Foundation (NSF Grant No. CBET- 0652859 and DMS$1115527)$ is greatly acknowledged.

\section{REFERENCES}

Carollo, F. G., V. Ferro and D. Termini. 2005. Flow resistance law in channels with flexible submerged vegetation, Journal of Hydraulic Engineering, 131(7), 554-564.

Chen, Q., P. A. Madsen and D. R. Basco. 1999. Current effects on nonlinear interactions of shallowwater waves, Journal of Waterway, Port, Coastal and Ocean Engineering, 125(4), 176-186.

Chen, Q., H. Zhao, K. Hu and S. L. Douglass. 2005. Prediction of wind waves in a shallow estuary. Journal of Waterway, Port, Coastal and Ocean Engineering, 131 (4): 137-148.

Chen, Q., L. Wang, H. Zhao and S. L. Douglass. 2007. Predictions of storm surges and wind waves on coastal highways in hurricane-prone areas. Journal of Coastal Research, 23, 1304-1317.

Chen, Q. and H. Zhao. 2012. Theoretical models for wave energy dissipation caused by vegetation, Journal of Engineering Mechanics, 138(2), 221-229.

Copeland, R. R. U. S. Army Corps of Engineers (2000). Determination of flow resistance coefficients due to shrubs and woody vegetation. CHETN-VIII-3

Dalrymple, R. A., J. T. Kirby and P. A. Hwang. 1984. Wave diffraction due to areas of energy dissipation, Journal of Waterway, Port, Coastal and Ocean Engineering, ASCE, 110(1), 67-79.

Dean, R. G. and C. J. Bender. 2006. Static wave setup with emphasis on damping effects by vegetation and bottom friction, Coastal Engineering, 53(1), 149-156.

Doncker, L. D., P. Troch, R. Verhoeven, K. Bal, P. Melre and J. Qulnteller. 2009. Determination of the manning's roughness coefficient influenced by vegetation in the river aa and biebrza river, Environmental Fluid Mechanics, 9, 549-567.

Freeman, G. E., W. J. Rahmeyer and R. R. Copeland (2000). Determination of resistance due to shrubs and woody vegetation. ERDC/CHL TR-00-25

Gedan, K. B., M. L. Kirwan, E. Wolanski, E. B. Barbier and B. R. Silliman. 2011. The present and future role of coastal wetland vegetation in protecting shorelines: Answering recent challenges to the paradigm, Climatic Change, 106, 7-29.

Jadhav, R. and Q. Chen (2012). Field investigation of wave dissipation by salt marsh vegetation during tropical cyclone. Proceedings of $33^{r d}$ International Conference on Coastal Engineering, July 1-6, Santander, Spain. 
Kouwen, N. and M. Fathi-Maghadam. 2000. Friction factor for coniferous trees along rivers, Journal of Hydraulic Engineering, 126(10), 732-740.

Kouwen, N. and R.-M. Li. 1980. Biomechanics of vegetative channel linings, Journal of the Hydraulics Division, Proceedings of the ASCE, 106(HY6), 1085-1103.

Li, C. W. and K. Yan. 2007. Numerical investigation of wave-current-vegetation interaction, Journal of Hydraulic Engineering, 133(7), 794-803.

Loder, N. M., J. L. Irish, M. A. Cialone and T. V. Wamsley. 2009. Sensitivity of hurricane surge to morphological parameters of coastal wetlands, Estuarine, Coastal and Shelf Science, 84, 625-636.

Lövstedt, C. B. and M. Larson. 2010. Wave damping in reed: Field measurements and mathematical modeling, Journal of Hydraulic Engineering, 136(4), 222-233.

Mendez, F. J. and I. J. Losada. 2004. An empirical model to estimate the propagation of random breaking and nonbreaking waves over vegetation fields, Coastal Engineering, 51(2), 103-118.

Nepf, H. M. and E. R. Vivoni. 2000. Flow structure in depth-limited, vegetated flow, Journal of Geophysical Research, 105(C12), 28547-28557.

Nikora, V., D. Goring, I. McEwan and G. Griffiths. 2001. Spatially averaged open-channel flow over rough bed., Journal of Hydraulic Engineering, 127(2), 123-133.

Patil, S. and V. P. Singh. 2009. Hydrodynamics of wave and current vegetation interaction, Journal of Hydrologic Engineering, 14(12), 1320-1333.

Resio, D. and J. J. Westerink. 2008. Modeling the physis of storm surge, Physics Today, 33-38.

Shepard, C. C., C. M. Crain and M. W. Beck. 2011. The protective role of coastal marshes: A systematic review and meta-analysis, PLOS ONE, 6(11).

Shih, S. F. and G. S. Rahi. 1982. Seasonal variations of manning's roughness coefficient in a subtropical marsh, Trans. of the ASAE, 25(1), 116-119.

Tsujimoto, T. and T. Kitamura. 1995. Lateral bed-load transport and sand-ridge formation near vegetation zone in an open channel, Journal of Hydroscience and Hydraulic Engineering, 13(1), 35-45.

Tsujimoto, T., T. Kitamura, Y. Fujii and H. Nakagawa. 1996. Hydraulic resistance of flow with flexible vegetation in open channel, Journal of Hydroscience and Hydraulic Engineering, 14(1), 47-56.

Wamsley, T. V., M. A. Cialone, J. M. Smith, J. H. Atkinson and J. D. Rosati. 2010. The potential of wetlands in reducing storm surge, Ocean Engineering, 37, 59-68.

Wamsley, T. V., M. A. Cialone, J. M. Smith, B. A. Ebersole and A. S. Grzegorzewski. 2009. Influence of landscape restoration and degredation on storm surge and waves in southern louisiana, Nat Hazards, 51, 207-224.

Wilson, C. A. M. E. 2007. Flow resistance models for flexible submerged vegetation, Journal of Hydrology, 342, 213-222.

Wilson, C. A. M. E. and M. S. Horritt. 2002. Measuring the flow resistance of submerged grass, Hydrological Processes, 16(13), 2589-2598.

Wu, F.-S., H. W. Shen and Y.-J. Chou. 1999. Variation of roughness coefficient for unsubmerged and submerged vegetation, Journal of Hydraulic Engineering, 125(9), 934-942. 
Zhao, H. and Q. Chen. 2012. Modeling attenuation of storm surge over deformable vegetation, submitted to Journal of Engineering Mechanics. 